\title{
Acute appendicitis and Enterobius vermicularis infestation
}

\author{
Rogeh Habashi MD, Michael Patrick Lisi MD
}

Cite as: CMAJ 2019 April 29;191:E477. doi: 10.1503/cmaj.181194

A 9-year-old Canadian boy presented to the emergency department with a 4-day history of sudden, unremitting pain in the right iliac fossa. His medical history was otherwise unremarkable, and he had not travelled recently. The patient was afebrile, and physical examination showed focal tenderness at the McBurney point. His total leukocyte count was 10.8 (normal 4.511.0) $\times 10^{9}$ cells $/ \mathrm{L}$ with a normal differential, and ultrasonography did not visualize the appendix. We diagnosed acute appendicitis and performed an urgent laparoscopic appendectomy.

After resecting a mildly inflamed appendix, we noticed that 8 live helminths dropped into the peritoneal cavity (Figure 1). All helminths were retrieved via endoscopic suctioning and a proviodine wash. We removed the appendix using a specimen retrieval bag. Tissue examination showed reactive lymphoid hyperplasia with intraluminal and submucosal pinworms (Appendix 1, available at www.cmaj.ca/lookup/suppl/doi:10.1503/cmaj.181194/-/DC1). Our patient recovered in 12 hours, and we administered 1 dose of albendazole in hospital with a prescription for a second dose in 2 weeks. We prescribed the same regimen as a preventive measure for household contacts. When informed of the findings, our patient reported a 1-week history of anal pruritus preceding his abdominal pain. He also recalled similar anal pruritus 2 years earlier when he had been diagnosed with Enterobius vermicularis (pinworm) infection, which was treated by pyrantel pamoate.

Although pinworm infestation is the most common intestinal helminth infection worldwide, simultaneous $E$. vermicularis infection and appendicitis is rare in Canada, accounting for less than $0.6 \%$ of all appendicitis presentations. ${ }^{1-3}$ It is likely that no causal relation exists between appendicitis and pinworm infection, as appendiceal inflammation is not typically found. ${ }^{2}$ Nocturnal anal pruritus remains the most important clinical symptom of $E$. vermicularis infestation, a result of female pinworms laying eggs within the anal verge at night. ${ }^{2,4}$ Laparoscopic appendectomy is the definitive treatment for appendicitis, followed by either mebendazole or albendazole for complete pinworm eradication. Prophylaxis is recommended for household contacts. ${ }^{2-4}$

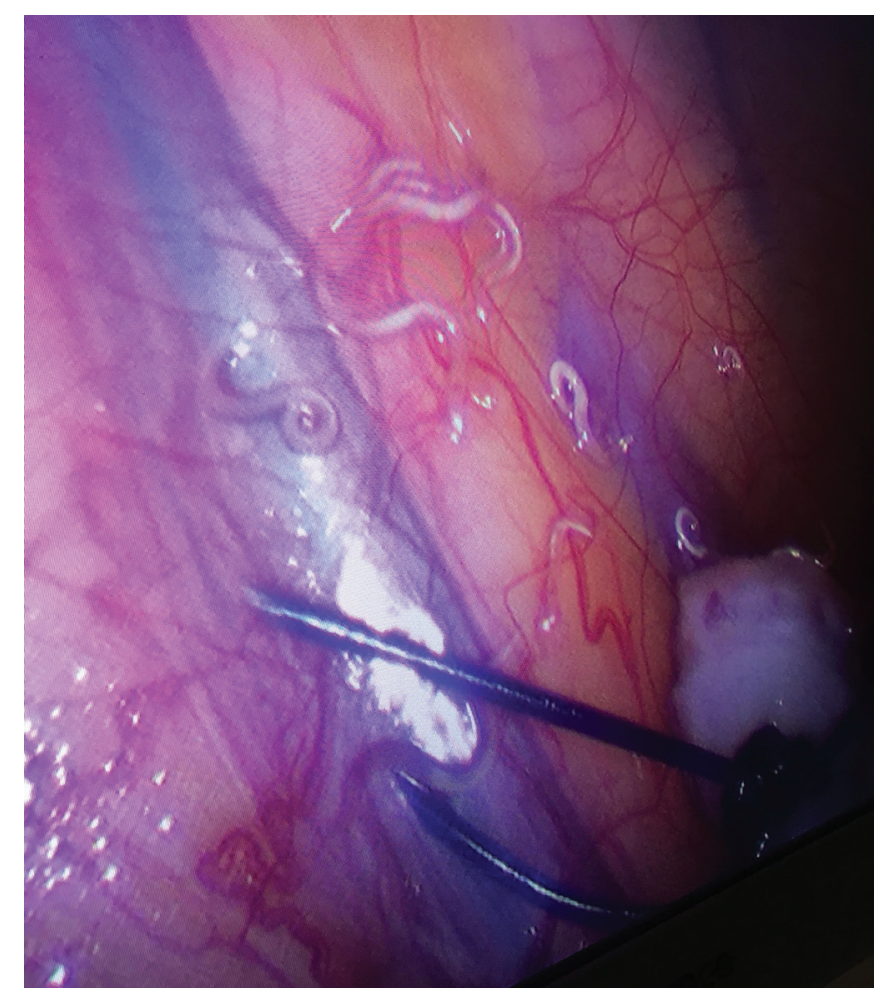

Figure 1: Multiple live Enterobius vermicularis are seen crawling from the inferior tip of the resected appendix within the peritoneal cavity of a 9-year-old boy with acute appendicitis.

\section{References}

1. Lagacé-Wiens PR, VanCaeseele PC, Koschik C. Dientamoeba fragilis: an emerging role in intestinal disease [published erratum in CMAJ 2006;175:777]. CMAJ 2006;175:468-9.

2. Efared B, Atsame-Ebang G, Soumana BM, et al. Acute suppurative appendicitis associated with Enterobius vermicularis: An incidental finding or a causative agent? A case report. BMC Res Notes 2017;10:494.

3. Lala S, Upadhyay V. Enterobius vermicularis and its role in paediatric appendicitis: Protection or predisposition? ANZ J Surg 2016;86:717-9.

4. Ariyarathenam AV, Nachimuthu S, Tang TY, et al. Enterobius vermicularis infestation of the appendix and management at the time of laparoscopic appendicectomy: case series and literature review. Int J Surg 2010;8:466-9.

\section{Competing interests: None declared.}

This article has been peer reviewed.

The authors have obtained parental consent.

Affiliations: Department of Surgery (Habashi, Lisi), McMaster University, Hamilton, Ont.; Department of Surgery (Lisi), Collingwood General and Marine Hospital, Collingwood, Ont.
}

Correspondence to: Michael Patrick Lisi, lisim@cgmh.on.ca 